\title{
Turismo y política pública argentina a partir de la Ley 25.997/05
}

\author{
Tourism and public policy in Argentina after the Law 25.997/05
}

Magali Florencia Luciano ${ }^{1}$ y Maria Belén Miranda ${ }^{2}$

\section{Resumen}

El presente trabajo tiene como objetivo indagar en la política pública turística argentina, a partir de la aplicación de la Ley Nacional de Turismo 25.997. Partiendo de un estudio documental, el análisis se focaliza en el redireccionamiento de la política pública turística que modificó ampliamente, en 2005, el posicionamiento del estado nacional respecto del sistema turístico nacional. Actualmente, luego de más de una década, la norma sobre la que se estructura la actividad parece mostrar ciertos signos de agotamiento, frente a una coyuntura influenciada por factores exógenos que, con el paso de los años, configuraron un escenario cada vez más caótico, desafiante y desordenado. Consecuentemente, este artículo realiza un análisis general, identificando éxitos y fracasos como también alcances y límites de la política pública nacional de esta compleja actividad en constante transformación y redefinición.

Palabras clave: políticas públicas, turismo, Ley Nacional de Turismo, sistema turístico nacional

\section{Abstract}

The aim of this research is to investigate the argentinian tourism policy based on the application of the National Tourism Law 25.997/05. Starting from a documentary study, the analysis focuses on the reorientation of tourism policy occurred in 2005. Since then, national state intervention regarding the national touristic system has been widely modified. Nowadays, over a decade later, the law in which tourism is structured seems not to respond to the increasingly chaotic, challenging, and disorderly scenario. Consequently, this article makes a comprehensive overview, identifying successes and failures as well as the scopes and limits of the national public policy of this complex activity in constant transformation and redefinition.

\footnotetext{
Recibido: 29 de septiembre de 2020 Aceptado: 20 de abril de $2021 \sim$ Publicado: 8 de julio de 2021

1 Estudiante de Licenciatura en Turismo. Facultad de Ciencia Política y Relaciones Internacionales. Universidad Nacional de Rosario. Correo electrónico: magaluciano49@gmail.com ID http://orcid.org/00000003-0757-4851

2 Estudiante de Licenciatura en Turismo. Facultad de Ciencia Política y Relaciones Internacionales. Universidad Nacional de Rosario. Correo electrónico: mariabelenmiranda95@gmail.com ID https://orcid.org/0000-0002-7143-0345
} 
Keywords: public policy, tourism, National Tourism Law, national tourism system

\section{Introducción}

El contexto como telón de fondo que motivó el redireccionamiento de la política pública objeto de este artículo, está conformado por partículas históricas que fueron erosionando el sistema turístico nacional con el correr de los años. El desarrollo de la práctica turística nacional inició a finales del siglo XIX, y en una primera instancia, dentro de los confines territoriales y librada al azar social. No obstante, la evolución de ésta, más su desgajamiento como actividad exclusiva de los sectores acomodados, hicieron que en el primer tercio del siglo XX, se posicionara como un sector que pugnaba, gradualmente, formar parte de la agenda política nacional.

Con el paso de los años esta intención se empezó a concretar bajo la escenificación pictórica y el diseño del paisaje nacional, cuyo principal fin era garantizar la unidad territorial y poblacional. Lo postulado declara que el turismo fue una de las actividades que desencadenó el tan anhelado progreso nacional. En este periodo, las políticas turísticas no emergieron exclusivamente del sector público, ya que fueron mayormente impulsadas desde instituciones privadas como el Touring Club Argentino. Así, se sancionó la Ley 12.699/39 y con ella el primer intento de política pública que, con una perspectiva federal, se remitió a impulsar el turismo. Los años precedentes, que jugaron un papel importante en la planificación de la actividad turística y, en consecuencia, en la política del sector, fueron los desarrollados entre 1946 y 1955. Por estos tiempos, el gobierno de Perón, a través de lineamientos políticos a favor del pueblo -como la política redistribucionista y el derecho a las vacaciones pagadas-, estableció un contexto beneficioso para los trabajadores, lo que derivó en la realización a nivel masivo de esta actividad de ocio.

En términos de la evolución histórica de la política pública turística en Argentina, el nítido período que tuvo lugar entre el 1958 y 1975 fue crucial, debido a que funcionó como la "antesala" de la Ley 25.997. Estos años estaban impregnados de una voluntad turística, desarrollada en el periodo anterior por la búsqueda de oportunidades para paliar las deficiencias de los países desarrollados suscitadas por la segunda posguerra. Asimismo, a inicios de los años 60, diferentes organismos internacionales de asistencia técnico-financiera -como la ONU, el FMI y el BM entre otros- dictaminaron que el turismo, como instrumento económico, sería uno de los sectores que ayudarían a concretar un efecto derivado en los países subdesarrollados, convirtiéndolos así en desarrollados. Este internacionalismo caló hondo en el territorio argentino ya obstaculizado por la viciada democracia. 
De este modo, el 30 de septiembre de 1958, en pleno desarrollismo argentino, se sancionó la Ley 14.574/58 y el turismo ingresó en la agenda política nacional desde una perspectiva diferente a la anterior, ya que se creía que esta estrategia complementaría al proceso de profundización de la industria nacional. De esta manera, se debía dar rienda suelta a la intervención de capitales extranjeros y demostrar -bajo la presión de las Fuerzas Armadas- un posicionamiento anticomunista. En otras palabras, la Ley 14.574/58 -con fundamentos “desperonizadores"- rigió la organización y funcionamiento de la Dirección Nacional de Turismo desde y con una mirada técnica, estructural e ideológica. A partir de la sanción de la norma, el Estado se posicionó como único actor decisivo y central en las políticas turísticas argentinas, relegando al sector privado a un nada consentido rol pasivo.

Por otro lado, siguiendo la línea de pensamiento de Schenkel (2017), entre los años 1983 y 2015, se dio una etapa de reconversión, "una reformulación de turismo social como asunto público" (p.51). La cultura pretoriana que marcó una historia cíclica de gobiernos de facto, logró desarticular el antes conquistado turismo social. El paso de un Estado benefactor a uno de corte neoliberal fue otro de los factores que colorearon una coyuntura donde el turismo como sector y actividad, empezó a ser una agregación de valor netamente económico, de crecimiento y de internacionalización, dentro de un período signado por una contracción Estatal, donde se vulneraron derechos mediante la pérdida de los ya conquistados.

Con el retorno a la democracia en el año 1983, se ubicó nuevamente al turismo social dentro de la agenda gubernamental. Así, el gobierno Alfonsinista reposicionó al sector, reconstituyendo por Decreto 663/87, a la Subsecretaría de Turismo Social, dentro de la Secretaría de Turismo. La Subsecretaría puso énfasis en la administración de las colonias estatales, la diversificación y la creación de ofertas turísticas de tinte social, y en desarrollar y ejecutar planes para grupos que tenían en común una menor cuantificación de recursos económicos, entre otros objetivos.

Este incipiente proceso fue dilatado por la crisis hiperinflacionaria, gestada en los últimos años de la década de los 80 bajo el gobierno de Menem. Su gestión estuvo caracterizada por tener más sombras que luces en el espectro económico y social. Sin embargo, en lo que al sector turístico se refiere, sus políticas resultaron un tanto contradictorias, debido a que si bien sus discursos fueron teñidos con intenciones populistas -acrecentados por un contexto internacional que lo acompañaba-, no concordaban con las manifestaciones empíricas de sus años de gobierno. Lo expuesto se puede patentizar en la privatización de Aerolíneas Argentinas, que no solo implicó una gran pérdida de capital activo para nuestro país, sino que también, desestabilizó el sistema turístico estatal después de una ideología desfavorecedora. 
En lo referente al turismo social, las políticas de reforma del Estado impulsadas por el gobierno menemista procuraron su fomento. De este modo, la Subsecretaría fue reemplazada por la Dirección de Turismo Social y Básico, también se llevaron adelante sustanciales reformas en la infraestructura, como el complejo de Chapadmadal. Posteriormente, esta Dirección fue reemplazada por la Dirección de Prestaciones Turísticas, tendiente a cerrar convenios con organismos públicos y privados para que participaran en esta actividad de ocio los jubilados, pensionados, y familias de bajos recursos. Sin embargo, el panorama político que regía condujo a altas tasas de desocupación y una flexibilización laboral que tercerizó aún más la situación de los trabajadores.

En este contexto, el turismo se convirtió en un elemento de atracción de divisas internacionales, necesarias para mitigar el déficit de la balanza de pagos y la ya adquirida y acrecentada deuda externa. A comienzos del siglo XXI el turismo de tipo receptivo -que se había posicionado en la década del 90 como uno de los objetivos claves-, continuó preponderante entre las políticas del sector, además de apostar nuevamente a la reconversión de un turismo social, convertido para ese entonces, en el saldo de la deuda de derechos perdidos en el transcurso de la historia.

En todo este proceso coexistieron designios encauzados en seguir apostando por un turismo social, pero las condiciones imperantes hicieron que ese turismo concebido y conquistado, ya para la década del 50 como un derecho, fuera truncado. La cierta estabilización concertada por el gobierno de Néstor Kirchner fue el andamiaje perfecto para que se estructurara al sector turístico, teniendo en cuenta la indispensable coordinación y cooperación público-privada, para desarrollar un turismo más inclusivo y desarrollista.

\section{Andamiaje teórico-conceptual}

Las políticas públicas carecen de significado único y, siguiendo el planteo de Subirats (2008), asumen características más bien polisémicas (p. 35). Esto deriva en la necesidad de construir analíticamente la noción de políticas públicas, bajo la óptica de la política pública en estudio.

De acuerdo con Oszlak y O'Donnell (1976), una política pública -en los términos de los autores de política estatal, implica continuidad, porque no refiere a un gobierno específico-:

Es un conjunto de acciones y omisiones que manifiestan una determinada modalidad de intervención del estado en relación a una cuestión que concita la atención, interés o movilización de otros actores en la sociedad civil. De dicha intervención puede inferirse una cierta direccionalidad, una determinada orientación normativa que previsiblemente afectará el 
futuro curso del proceso social hasta entonces desarrollado en torno a una cuestión (Oszlak y O'Donnell 1976: 112).

De acuerdo con la mirada de los autores, las políticas públicas son descritas como reveladoras del posicionamiento del Estado en acción; es decir, cada vez que el Estado toma una posición, ya sea por acción o inacción frente a una cuestión, en favor de resolverla. Esas "acciones u omisiones" no deben entenderse como un acto reflejo o una respuesta aislada, sino como la manifestación de una determinada forma de intervención estatal con relación a una "cuestión" que es problematizada cuando parte de la sociedad que cree que hay que hacer algo para, en cierto modo, zanjarla.

Asimismo, la toma de posición del Estado "no tiene por qué ser unívoca, homogénea ni permanente. De hecho, suele ser todo lo contrario" (Oszlak y O’Donnell, 1984, p. 112), siendo muchas veces el puntapié de nuevas políticas públicas. Este enfoque plantea el estudio de las políticas públicas, en términos de Aguilar Villanueva (1992), desde una perspectiva descriptiva, planteándola como una decisión política emanada especialmente desde el gobierno (p.22).

Siguiendo una línea de pensamiento bastante similar a la de los autores recién mencionados, Mény y Thoenig (1989) sustentan que una política pública puede ser entendida como el resultado de la actividad de una autoridad investida de poder público y de legitimidad gubernamental, que se presenta bajo la forma de un conjunto de prácticas y normas que emanan de uno o varios actores públicos (p.129). Por "público" refieren a la actividad humana atravesada por la regulación o intervención gubernamental o social (Parsons, 2007), el campo de interacciones en el que los individuos se convierten en ciudadanos, donde los ciudadanos por sí mismos o a través de organizaciones, hacen política y hacen las políticas (Aguilar Villanueva, 1993, p. 7).

Desde un enfoque de la construcción teórica:

Las políticas públicas pueden ser entendidas como un proceso social complejo, a lo largo del cual es posible ver desagregados en su accionar a los sectores de los aparatos estatales y también a sectores de la sociedad, que bajo formas institucionalizadas y en torno a una cuestión configuran campos de relaciones sociales al adoptar sucesivas tomas de posición y actuar en consecuencia transformando la realidad (Díaz, 1998, p. 8).

La conceptualización de la autora refiere a las políticas públicas, como un proceso que implica necesariamente decisiones e interacciones de los diferentes involucrados en la arena política y no como el mero posicionamiento del Estado en un momento determinado y frente a una situación específica.

Reforzando la idea anterior, Subirats et al (1992) aseveran que una política pública no solo debe incluir las reglas, sino también las decisiones correspondientes 
a todas y cada una de las etapas de la acción pública y los actos individuales y concretos producidos durante la ejecución de estas (p.37).

El análisis de esta investigación parte de considerar a las políticas públicas desde una mirada global y teniendo en cuenta diferentes aspectos de lo esbozado por los teóricos mencionados. Desde este enfoque, las políticas públicas son un fenómeno complejo, multidimensional, enmarcado en coyunturas específicas, que se desarrollan en distintas arenas en las que interactúan actores con intereses, racionalidades, recursos de poder disímiles, pero que inciden en el proceso total.

Así, se visualiza la idea de políticas públicas como el conjunto de las actividades estatales o sociales materializadas a través de un determinado tipo de intervención o no, que busca hacer frente a una situación o a varias que son problemáticas, con el propósito de lograr ciertos objetivos perfectamente delimitados en concordancia con un programa estatal o con demandas provenientes de ciertos actores, articulando estrategias, acciones, instrumentos, recursos, etc.

\section{Redireccionamiento de la Política Pública en Argentina: la Ley Nacional de Turismo 25.997/05}

Esta ley fue sancionada el 5 de diciembre de 2004, durante la presidencia de Néstor Kirchner y constituyó un instrumento estratégico fundamental, como afirma Schenkel (2018), ya que el turismo deja de ser institucionalizado como actividad recreativa para ser determinado como una actividad económica de gran importancia (p12.). Para su redacción se tomaron elementos de las diferentes leyes en materia turística que ya existían en Sudamérica, así como también, instrumentos normativos de la Organización de Naciones Unidas (ONU), como los Objetivos para el Milenio, los Lineamientos de Sustentabilidad de la Organización Mundial del Turismo (OMT) y el Plan Estratégico Territorial 2016. Así se declaró de interés nacional al turismo como actividad socioeconómica estratégica y esencial para el desarrollo del país y, en este sentido, prioritaria dentro de las políticas del Estado (Ley 25.997/05, art. 1). Al mismo tiempo, se sentaron las bases para el desarrollo de la actividad con una visión federal y de manera sustentable y sostenible.

En este sentido, el propósito de la norma jurídica no solo fue darle mayor participación al sector privado, sino también reivindicar la política turística social. La ley buscó estabilizar el sistema turístico nacional desde una perspectiva social, en términos de los beneficios sociales que plantea. En este sentido, explicita como su objeto:

El fomento, el desarrollo, la promoción y la regulación de la actividad turística y del recurso turístico, mediante la determinación de los mecanismos necesarios para la creación, conservación, protección y 
aprovechamiento de los recursos y atractivos turísticos nacionales, resguardando el desarrollo sostenible y sustentable y la optimización de la calidad, estableciendo los mecanismos de participación y concertación de los sectores público y privado en la actividad (Ley 25.997/05, art. 1).

De allí se desprenden los principios rectores que deberían guiar la gestión turística desde todas las esferas (Ley 25.997/05, art. 2):

1. Facilitación. Por el que adquiere la responsabilidad de "posibilitar la coordinación e integración normativa a través de la cooperación de los distintos organismos relacionados directa o indirectamente con la actividad turística, persiguiendo el desarrollo armónico de las políticas turísticas de la Nación”.

2. Desarrollo social, económico y cultural. De este modo se declara al turismo como "un derecho social y económico de las personas dada su contribución al desarrollo integral en el aprovechamiento del tiempo libre y en la revalorización de la identidad cultural de las comunidades".

3. Desarrollo sustentable. Ya que "el turismo se desarrolla en armonía con los recursos naturales y culturales a fin de garantizar sus beneficios a las futuras generaciones. El desarrollo sustentable se aplica en tres ejes básicos: ambiente, sociedad y economía”.

4. Calidad. Considerando "prioridad optimizar la calidad de los destinos y la actividad turística en todas sus áreas a fin de satisfacer la demanda nacional e internacional”.

5. Competitividad. La ley pretende "asegurar las condiciones necesarias para el desarrollo de la actividad a través de un producto turístico competitivo y de inversiones de capitales nacionales y extranjeros".

6. Accesibilidad. Implica "propender a la eliminación de las barreras que impidan el uso y disfrute de la actividad turística por todos los sectores de la sociedad, incentivando la equiparación de oportunidades".

La ley, en tanto es una cristalización de la toma de posición por parte del Estado en torno a una cuestión socialmente problematizada, simplemente muestra la postura del Estado, pero no sus efectos. En este sentido y conscientes del dinamismo que presenta la actividad turística, la política pública turística debe ser analizada, consecuentemente, en términos de proceso, teniendo en cuenta la complejidad del juego político que genera. Sin lugar a duda, la Ley Nacional de Turismo del 2005 es entonces un redireccionamiento de la política pública turística argentina, motivada además, por un cambio de paradigma en la gestión turística a nivel internacional, como así también y en sentido baumeano, una mayor liquidez social y tecnológica. Este cambio es fácilmente visible al analizar el rol del Estado argentino en la administración turística, que pasó desde una posición estrictamente funcional a 
facilitadora, posicionándose como un actor clave en la gestión turística nacional, con el deber de "promover y coordinar la apertura de los procesos de decisión con los diferentes actores involucrados en al área turística” (Schenkel y Ercolani, 2015, p. 2)

Partiendo de esa premisa, los signos de agotamiento de la Ley 14.574/58 se agudizaron post crisis del 2001 y se instaló la cuestión en la agenda política, debido a que los actores involucrados en el sector empezaron a detectar una problemática que debía ser atendida, presionaron para que ese asunto pasara a la agenda gubernamental y una vez allí, este proceso decantó en la sanción de la nueva Ley. Un dato de importancia esclarecedora es que tanto la Ley 14.574/58 como la 25.997/05 no solo se realizaron para resolver un problema socialmente determinado como público, sino también, como un instrumento estratégico que permitiera implementar un proyecto político y un modelo de desarrollo, con una gran penetración internacionalista. Esta suerte de síntesis no solo es el "protomodelo" a partir del cual Oszlak y O'Donnell (1976) sugieren no estudiar a las políticas públicas, sino qué es una política pública.

Luego de cuatro gestiones a partir de su sanción, la norma jurídica que reemplazó a la del gobierno de Arturo Frondizi, mantiene su vigencia sin actualizaciones ni cambios sustanciales. Su intencionalidad es clara: el fomento, el desarrollo, la promoción y la regulación de la actividad turística y del recurso turístico, mediante la determinación de los mecanismos necesarios para la creación, conservación, protección y aprovechamiento de los recursos y atractivos turísticos nacionales, resguardando el desarrollo sostenible y sustentable, y la optimización de la calidad, estableciendo los mecanismos de participación y concertación de los sectores público y privado en la actividad. Asimismo, además de los principios rectores ya mencionados, algunos autores como Aramburu, señalan que existe otro principio implícito, el de Defensa del Turista.

Las nueva ley nacional planteó en su articulado no irrumpir competencias locales inherentes a las provincias. Así, conservaron dentro de las competencias correspondientes, la autonomía respecto de la planificación de su propia política turística, siempre que esta legislación no atente a la intencionalidad de la ley madre y la promoción del turismo en lo relativo a su extensión territorial.

\section{Entramado actoral establecido en la Ley Nacional de Turismo}

La ley es bastante clara, en términos de los actores que considera imprescindibles para la actividad y sus respectivas funciones. Más allá de que tampoco existe una definición unívoca de actor dentro del universo académico de las políticas públicas, de acuerdo con la propuesta de Subirats et al (1992), como actor puede considerarse a un individuo, a varios individuos, o también una persona jurídica, o incluso un 
grupo social (p. 49). Dado que la política turística involucra una gran cantidad de participantes que actúan, directa o indirectamente, en la toma de decisiones, es pertinente partir el análisis desde esta amplia definición.

Por otro lado, las investigadoras Schenkel y Ercolani (2015), realizan un análisis actoral en torno a la política pública turística argentina, que surge de la aplicación de la ley nacional en cuestión. Sin embargo, su estudio es altamente formal, jurídico e institucional, y está centrado exclusivamente en el contenido de la ley, ignorando la praxis. De este modo, arriban a una clasificación un tanto elitista, que deja por fuera del juego político a ciertos grupos sociales, a quienes Subirats reconocería como "actores pasivos". Actores que, si bien no participan del juego político, son afectados fuertemente, de manera positiva o negativa, por las decisiones, como la comunidad receptora -en palabras de Schenkel y Ercolani; el actor mencionado no es incluido en la clasificación que presentan, debido a que aún no se puede afirmar que ocupe un lugar relevante dentro del sistema turístico-.

De igual manera, reconociendo las limitaciones propias de una ley de esta magnitud, es dificultoso llegar a la mínima unidad elemental de sentido, para analizar y describir puntillosamente a cada uno de los actores, ya que exigiría de un análisis por demás meticuloso e inabarcable. Los actores que presenta la ley, en concordancia con la clasificación de Subirats, son:

La Secretaría de Turismo (actualmente Ministerio de Deportes y Turismo a cargo de Matías Lammens) como actor público-político administrativo, encargado de aplicar la ley.

El Consejo Federal de Turismo, organismo público-político administrativo de carácter federal y consultivo para la autoridad de aplicación. Sus funciones son "examinar y pronunciarse sobre cuestiones referentes a la organización, coordinación, planificación, promoción, legislación y estrategias de las actividades turísticas de carácter federal" (Ley 25.997/05, art. 10).

El Ministerio de Economía como ente público, también de carácter político administrativo encargado del Sistema Nacional de Inversiones Públicas. Se encarga de la formulación, gestión y financiación de planes de inversiones y proyectos con interés turístico.

El Consejo Interministerial de Facilitación Turística como organismo público, político y administrativo, garantiza y coordina el cumplimiento de las funciones administrativas de las distintas entidades públicas de nivel nacional.

La Administración de Parques Nacionales como actor público político y administrativo es un organismo descentralizado cuyo propósito es el de "diseñar, conducir y controlar la ejecución de las políticas necesarias para conservar y manejar 
los Parques Nacionales, Monumentos Naturales y Reservas Nacionales" (Argentina.gob.ar).

El Instituto Argentino de Normalización y Centralización que configura una asociación civil sin fines de lucro de la esfera privada, cuyo objetivo es la mejora de la competitividad, el desarrollo sostenible y la calidad de vida del ciudadano.

La Cámara Argentina de Turismo es también una asociación civil y representa a las principales empresas asociadas a la actividad turística del país. Su fundación tuvo lugar en 1966, varios años antes de la nueva Ley Nacional de Turismo. Con el objeto de "promover el desarrollo masivo y racional de la industria turística" (Proyecto de Resolución Cámara de Diputados de la Nación, 2010), se reposiciona a partir de la nueva norma jurídica, en representación de la esfera privada.

Los turistas, que si bien no participan en decisiones políticas, son actores de la esfera privada, que deciden sobre sus prácticas y elegirán o descartarán lugares y actividades de acuerdo con sus intereses.

Tanto el Instituto de Normalización y Centralización como la Cámara Argentina de Turismo y los turistas son beneficiarios finales, debido a que serán afectados directamente por la problemática que esté en cuestión y por los resultados de la posición que adopte el poder público.

Por su parte, la comunidad receptora es un grupo tercero que se convertirá en beneficiaria o afectada, directa o indirectamente por esta ley y por sus efectos inevitablemente derivados. Su rol, bajo la óptica de esta política pública, es pasivo pero central, ya que son los que influirán en el éxito o el fracaso de un destino.

Un dato no menor es que algunos académicos -como Subirats-que al momento de clasificar actores no emplean una categoría que especifique a aquellos entes $\mathrm{u}$ organismos que se articulan de manera público-privada. Dentro de esta articulación mixta se ubica el Instituto Nacional de Promoción Turística (INPROTUR), organismo creado por la Ley 25.997/05 como medio para promocionar el turismo receptivo y la imagen del país. Su objeto es "desarrollar y ejecutar los planes, programas y estrategias de promoción del turismo receptivo internacional y de los productos directamente relacionados con él, así como de la imagen turística del país en el exterior" (Ley 25.997/05, artículo 14). De este modo, pretende posicionar a la Argentina como destino predominante entre los mercados emisores. Dicho organismo no solo integra a miembros de ambos sectores en su directorio, sino que también posee una financiación mixta. 
Gráfico 1. Sector turistico a partir de la Ley Nacional de Turismo

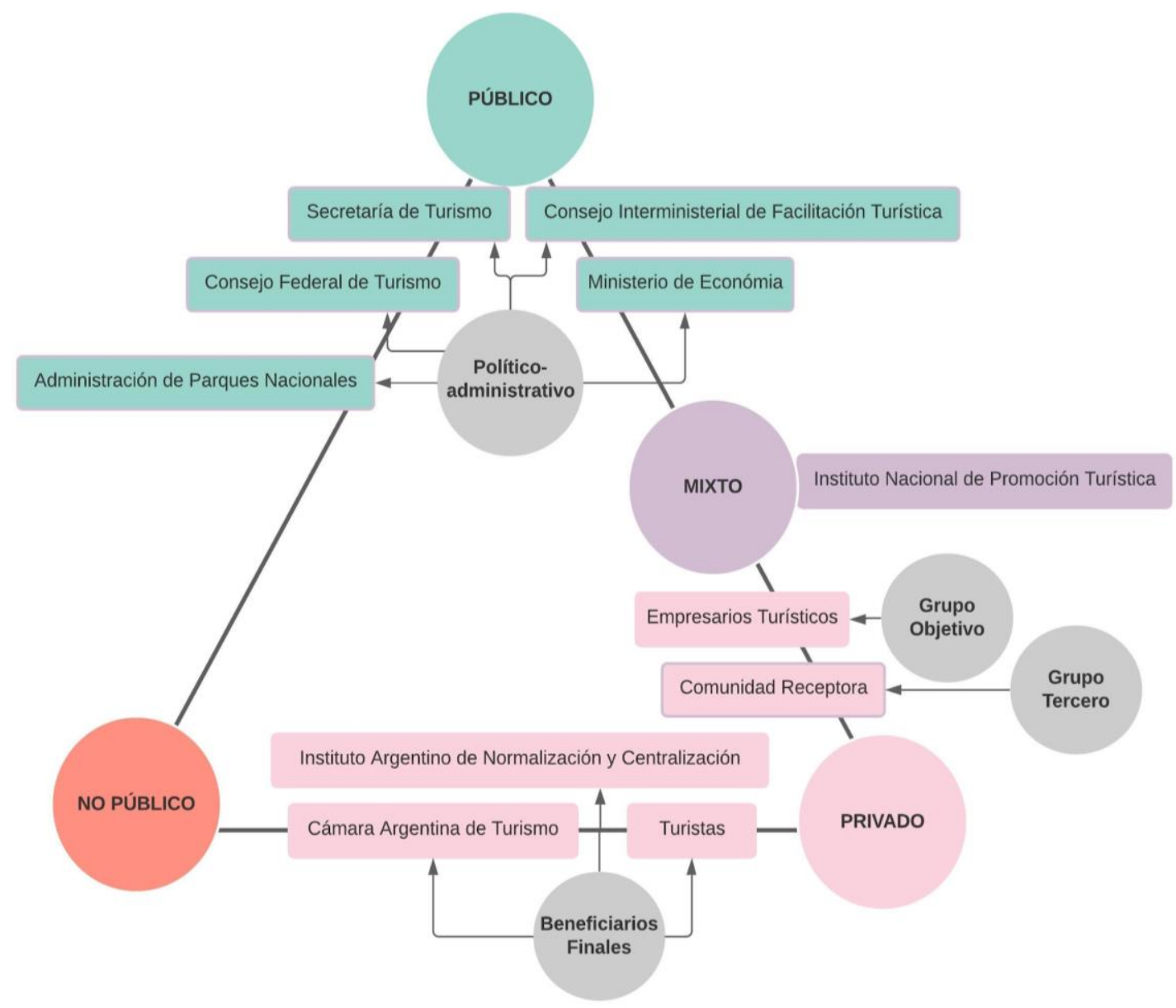

Fuente: Elaboración propia a partir del triángulo de actores propuesto por Subirats et. al (2018)

\section{Puesta en marcha}

La creación de una norma jurídica no basta para que automáticamente sus efectos comiencen a surtirse, se necesita de cierto marco que haga posible su implementación y la ejecución de lo estipulado. Este tramo del proceso es incluso aún más determinante para el éxito de una política pública que su propia formulación. De este modo y como primer paso para el redireccionamiento de la política pública turística en Argentina, se promulgó el 27-09-2006, el Decreto Reglamentario 1297/2006 que formalizó de una vez y para siempre la Ley 25.997/05.

Con anterioridad al decreto, autoridades de la Secretaría de Turismo de la nación, empresarios del sector privado y funcionarios provinciales iniciaron reuniones que llevarían a la concreción, de acuerdo con el artículo 7 de la ley, de un Plan Federal Estratégico que determinaría la manera en que se llevaría adelante no solo la aplicación de la ley, sino también la política pública en materia de turismo. Así, de acuerdo con los objetivos previstos en la ley y reafirmando la primacía de un enfoque top down que acentuaba la jerarquía indiscutible del sector público como actor central, 
se llevaron adelante talleres en diferentes regiones vinculadas fuertemente con el turismo que tenían como objetivo formular el Plan Estratégico.

Finalmente, luego de diez meses de trabajo conjunto, emergió el Plan Federal Estratégico de Turismo Sustentable 2016 (PFETS 2016). Si bien se estipula que se desarrolló en concordancia con una multiplicidad de actores, precisamente más de quinientos, provenientes de los sectores público, privado y académico; quienes firmaron el acuerdo de compromiso fueron: el Consejo Federal de Inversiones (que no figura expresamente en la norma), la Administración de Parques Nacionales, el Consejo Federal de Turismo en representación de las Provincias del país, la Cámara Argentina de Turismo y la Subsecretaría de Turismo de la Nación como autoridad. Así, se establecieron las líneas de acción hasta 2016, con el principal propósito de posicionar a Argentina como un país turístico indiscutido de Suramérica, con una oferta atractiva en términos de su amplitud y diversidad.

El PFETS 2016, con una intencionalidad democrática y representativa, reafirmó la división del territorio nacional en diferentes regiones: Buenos Aires, Córdoba, Litoral, Cuyo, Patagonia y Norte; sustentandose en los principios de la Ley de Desarrollo con Inclusión y Conservación del Patrimonio Turístico Nacional.

Ahora bien, este plan fue actualizado en dos ocasiones. En 2011 amplió su proyección al 2020 e introdujo modificaciones en lo referente al diseño operativo. La visión que motivó esa actualización fue la misma del 2006:

Constituir el país mejor posicionado de la región desde el punto de vista turístico basándose en la diversidad de la oferta y la calidad de sus servicios, pero sin descuidar el desarrollo territorial equilibrado y el respeto por el hábitat e identidad de la población (Plan Federal Estratégico de Turismo Sustentable 2020: 2011, p.12).

Posteriormente, en el 2015, el Plan Federal volvió a actualizarse extendiendo su horizonte temporal a 2025. En esta ocasión, se planteó una revisión mucho más profunda e integral que inició en el 2013 con ocho foros de Diálogo Sectorial Turístico, a lo largo y ancho del territorio nacional. El propósito principal tenía que ver con develar las problemáticas por las que todo el sector se encontraba atravesando y de ese modo, redirigir los esfuerzos y ajustar lo que hiciera falta. Así, el estudio abarcó a un gran abanico de afectados del sector público, privado y académico.

La motivación principal de esta nueva actualización radicaba en lo mucho que había cambiado el contexto nacional e internacional, desde la puesta en marcha del PFET 2020 que ya no estaba dando respuestas a los sectores. En línea con lo anterior se establecieron nuevas perspectivas: política, económica, social y ambiental; relación con los mercados; relación destino - turista - residente; actividades y procesos e infraestructura. 
De este modo, el PFTS 2025 incorporó nuevas figuras como principales actores institucionales del turismo nacional. Así, a la Cámara Argentina de Turismo, la Cámara Federal de Inversores, el Comité Interministerial, el Ministerio de Turismo y la Administración de Parques Nacionales, se sumaron el Consejo de Decanos y Directores de Unidades Académicas relacionadas con la Enseñanza del Turismo (CONDET), el Consejo Federal de Directivos de Turismo de Universidades de Gestión Privada (CONFEDIT), Aerolíneas Argentinas y el Instituto de Calidad Turística Argentina.

El Plan Federal de Turismo Sustentable 2025 le dio un lugar relevante al sector académico público y privado dentro de la actividad. Al mismo tiempo, determinó como actor clave para el sector, al Instituto de la Calidad Turística Argentina (ICTA), que se creó en 2013 como una entidad de conformación mixta, financiado por el Ministerio de Turismo. Su objeto es:

Impulsar el desarrollo, excelencia y crecimiento de la actividad turística, y procurar la promoción de la cultura de la calidad en materia de turismo y fomentar la adopción de criterios y sistemas de gestión de la calidad, en y para todos los artífices de la actividad turística, tanto del sector público y privado (Instituto de la Calidad Turística Argentina, 2020).

En lo que a ley respecta, el Fondo Nacional de Turismo incurrió en alteraciones en los años 2014 -por Ley 27.008 y 2016 por Ley 27.341-, que amplió el plazo de vigencia por 10 años más y la modificación del Impuesto DNT -gravamen a los pasajes al exterior- de un $5 \%$ a $7 \%$ respectivamente.

Con el correr de los años, la columna vertebral del turismo nacional se complementó con otros instrumentos normativos, como la Ley 26.208 de Turismo Estudiantil, que a partir de la institución de un fondo fiduciario, garantizó y reguló la manera en que los viajes de estudiantes se llevaban adelante, de este modo previno el fraude y la especulación que conducía a la quiebra de muchas empresas de viajes.

\section{Evaluación de la Ley 25.997/05}

Si bien no es una ley realmente antigua y su contenido es bastante actual, hay ciertas temáticas que hoy son sustanciales para nuestro mundo y no están contenidas en la norma jurídica, posiblemente porque al momento de su creación no habían surgido o no tenían gran presencia en la palestra global.

La noción de cambio climático se volvió fundamental a partir del Acuerdo de París del 2015, que busca la transformación de los países firmantes hacia un modelo de desarrollo equitativo, bajo en carbono y resiliente al cambio climático. Si bien, Argentina forma parte de la Convención Marco de las Naciones Unidas sobre el Cambio Climático (CMNUCC) y lleva adelante tímidas acciones en materia de 
cambio climático, los objetivos que plantea la convención no fueron contemplados en la ley, por tratarse de algo posterior. Por este motivo, en una futura actualización de esta norma jurídica deben tenerse en cuenta, además de los elementos ya referidos, los 17 Objetivos de Desarrollo Sostenible (ODS) presentados por la ONU, ya que constituyen una herramienta interesante para mitigar la pobreza en el mundo, resguardar el planeta y mejorar las vidas y las perspectivas de las personas en todo el mundo.

Asimismo, hay ciertas contradicciones al interior de la norma jurídica. En el inciso b del artículo 12 -que refiere a las atribuciones del Consejo Federal de Turismodictamina: "convocar a entidades públicas y privadas a la asamblea, como miembros no permanentes con voz, pero sin voto" (Ley 25.997/05). Esto resulta un tanto contradictorio con el artículo 1 de la ley, cuando declara que la "actividad privada es una aliada estratégica del Estado" (Ley 25.997/05), ya que al mismo tiempo no se le otorga al sector privado un espacio permanente aunque con voz pero no de voto. Elementos sumamente necesarios para una verdadera colaboración público-privada en el sector.

Por otro lado, el Consejo Interministerial de Facilitación Turística no cuenta con una agenda de trabajo demasiado clara. De hecho se registran muy pocas reuniones concertadas desde la creación del organismo. El turismo es una actividad realmente transversal con muchos sectores y, en consecuencia, con Ministerios por lo que podría ser de gran utilidad un planeamiento periódico que permita no solamente intercambiar posicionamientos entre los actores involucrados de forma directa en la actividad, sino también con aquellos actores vinculados indirectamente al turismo,, ya que son los gestores -desde un espectro tangible e intangible- de la base sobre la que el mismo se posiciona.

En correlación con lo anterior, si bien dentro de la ley se menciona a las comunidades receptoras y a los turistas como figuras necesarias para la actividad, es necesaria una inclusión real de estos actores que surgen de la esfera social y privada en la arena política turística. Estos, en su mayoría son afectados o beneficiados, directa o indirectamente, por los cambios que pueda atravesar la actividad, por lo que su involucramiento a partir de un organismo sería sumamente interesante.

Por otro lado, también hay contradicciones al interior de la norma. En el inciso b) del artículo 12 de la norma -artículo que refiere a las atribuciones del Consejo Federal de Turismo- dictamina: "convocar a entidades públicas y privadas a la asamblea, como miembros no permanentes con voz, pero sin voto" (Ley 25.997/05). Esto resulta un tanto contradictorio con el artículo 1 de la ley cuando declara que la "actividad privada es una aliada estratégica del Estado" (Ley 25.997/05) ya que al mismo tiempo no se le otorga al sector privado un espacio permanente y tampoco 
voz de voto. Elementos sumamente necesarios para una verdadera colaboración público-privada en el sector.

Además, en el Anexo I de la ley bajo análisis, cuando se enumeran las actividades vinculadas directa e indirectamente al sector turístico, conforme a la Clasificación Internacional Uniforme de las Actividades Turísticas de la Organización Mundial del Turismo, no hay mención expresa a las actividades desempeñadas por el Sector Educativo y de Formación Profesional. Esto configura un gran error, ya que todas las mencionadas, desde la óptica de la eficacia, son actividades derivadas de ese sector.

En el tercer párrafo del artículo 1 se determina además de que la ley tiene como objeto "el fomento, el desarrollo, la promoción y la regulación de la actividad turística y la optimización de la calidad" (Ley 25.997/05). Esta última tiende a posicionar al Estado desde un lugar ambiguo, ya que es este, bajo la institución gubernamental que representa y coordina al sector turístico, quién debe velar por que los derechos de los consumidores sean respetados, garantizados y cumplidos según lo especificado. Si el Estado no hace esto a nivel legislativo y en consonancia empírico, las jurisdicciones provinciales y municipales no estarán taxativamente, desde una óptica constitucional, obligadas a hacerlo.

\section{Conclusiones}

La Ley 25997/05 encarnó un gran avance, tomando como referencia la ley precedente, en términos de la vinculación del turismo y el rol del Estado. La trascendencia de este redireccionamiento de la Política Pública más el andamiaje histórico que impulsó su creación, fue tal que desde entonces el turismo es un elemento indiscutido y prioritario dentro de la agenda política nacional, no solo como atractor de divisas extranjeras, sino también como factor de desarrollo económico y social.

Formulada desde una óptica cooperativa entre el sector público y privado, posiciona a la actividad privada como "aliada estratégica del Estado", donde este último es el constructor y organizador del esqueleto turístico a nivel nacional y derivador de repercusiones internacionales a nivel de las campañas de promoción turística. De igual manera, esclarece, según parámetros internacionales, a los actores vinculados directa e indirectamente con la actividad, determinando así cierta organización y especialización de la actividad en los confines territoriales. Además, y por primera vez en Argentina, se gestó un Plan que ordenara las líneas de acción para el desarrollo de la actividad, con una visión integradora, federal y con el sector privado ya no más como mero espectador sino como aliado y participe -aunque con algunas deficiencias en la estructura turística determinada por la ley, como ya se ha evidenciado en las críticas-. 
Esta política pública turística, al materializarse en una serie de instituciones derivadas de la Ley 25.997, no sólo organizó, como ya había ocurrido anteriormente, al sector turístico a nivel interno, sino que creó oportunidades para posicionar a Argentina, desde la cristalización y ejercicio del INPROTUR, como un destino turístico internacional entre los mercados emisores de potenciales turistas. Así, el número de turistas arribados aumentó considerablemente y permitió consolidar, de esta manera y gracias a las acciones del Plan Estratégico de Marketing Turístico, un turismo receptivo acrecentador de un desarrollismo económico y, por efecto derivado, social y cultural.

Más allá de los notables beneficios que acompañan a la actividad turística y la constante actualización de los planes de gestión, sería interesante actualizar la norma jurídica de manera taxativa, manteniendo su posición de aliada del turismo sustentable e inclusivo, pero expandiendo sus horizontes a debates mucho más actuales. Si bien estas nociones se plasmaron en el Plan Federal Estratégico de Turismo Sustentable 2020 y, fundamentalmente en el del 2025, es importante minimizar las lagunas legales y las políticas forjadoras de posibles disyuntivas futuras.

Para concluir y reafirmando el posicionamiento empírico esgrimido, la sanción de la Ley 25.997 fue la que construyó a partir de una escasa estructura turística a nivel país, deteriorada por la evolución de un panorama internacional globalizado y por una complicada trascendencia histórica nacional que dejó obsoleta la Ley 14.574/58, los cimientos políticos-administrativos que procuran regular y planificar el desarrollo del turismo. Esto se constituyó en un problema socialmente determinado como público, desenvuelto por la confección de diferentes actores, en esta política pública.

\section{Referencias bibliográficas}

Aguilar Villanueva, L.F. (1992). "La hechura de las políticas", M.A Porrúa Grupo Editorial, México.

Aguilar Villanueva, L.F.(1993). "La implementación de las políticas", M.A Porrúa Grupo Editorial, México. Recuperado de: http://ibcm.blog.unq.edu.ar/wpcontent/uploads/sites/28/2014/03/EYPP_Aguilar_Villanueva_2_Unidad_2. pdf

Texto Institucional del Ministerio de Ambiente y Desarrollo Sostenible sobre los Parques Nacionales. Página Oficial de la Nación Argentina, https://www.argentina.gob.ar/parquesnacionales/institucional

Díaz, C. (1998) "El ciclo de las políticas públicas locales: notas para su abordaje y reconstrucción", en Venesia, J. (comp.) "Políticas públicas y desarrollo local”. I.D.R. -Instituto de Desarrollo Regional. Rosario. 
Instituto de Calidad Turística Argentina. Sección “Acerca del ICTA-Quienes Somos”. Recuperado

http://www.icta.org.ar/page/quienes\#: :text=El\%20ICTA\%20es\%20una\%20 fundaci\%C3\%B3n,la\%20actividad\%20tur\%C3\%ADstica\%2C\%20tanto\%20del

Meny, Y. y J.C. Thoenig (1989) "Le politiche publiche”. Il Mulino, (Bologna, 1991) o P.U.F. Paris.

O'Donnell, G. y O. Oszlak (1976). "Estado y políticas estatales en América Latina". CEDES, Bs. As.

Parsons, W. (2007) "Políticas Públicas. Una introducción a la teoría y la práctica del análisis de políticas públicas”. Miño \& Dávila, coeditado con FLACSOMéxico. $1^{\text {a }}$ edición 2007.

Schenkel, Erica.(2018).”La Evolución de la Política Turística en Argentina. Un análisis de sus finalidades ". Revista Lider $N^{\circ}$ 35.PP 9-26

Schenkel, Erica y Ercolani, Patricia. (2015)."Los actores de la Politica Turística Argentina a partir de la nueva Ley Nacional de Turismo " Simposio; VII Simposio Internacional y XIII Jornadas Nacionales de Investigación Acción en Turismo CONDET 2015. Innovación sustentable para el turismo y la recreación; 2015.

Subirats, J.; P. P. Knoepfel; C. Larrue y F. Varonne (2008). Análisis y gestión de Políticas Públicas, Cap. 2 "Las Políticas Públicas” y Cap. 3 "Los actores de las políticas públicas", Editorial Ariel, Barcelona.

\section{Documentos oficiales}

Cámara de Diputados de la República Argentina(2010). Proyecto de Resolución :Declarar de interés de esta H.Cámara el Primer Congreso Internacional de Turismo del 10.Buenos Aires, Argentina. Recuperado de :https://www.hcdn.gob.ar/proyectos/proyectoTP.jsp?exp=3638-D-2010

Ministerio de Justicia y Derechos Humanos. Presidencia de la Nación. (1958). Ley Nacional de Turismo. Sistema Argentino de Información Jurídica. Buenos Aires. Recuperado de: http://www.saij.gob.ar/legislacion/ley-nacional14574.htm

Ministerio de Justicia y Derechos Humanos. Presidencia de la Nación. (2005). Ley Nacional de Turismo. Ministerio de Justicia y Derechos Humanos. Buenos Aires. Recuperado de:

http://servicios.infoleg.gob.ar/infolegInternet/anexos/100000104999/102724/norma.htm

Ministerio de Turismo. Presidencia de la Nación (2015). Plan Federal Estratégico de Turismo Sustentable 2015. Recuperado de: 
https://www.mininterior.gov.ar/planificacion/pdf/Plan-Federal-

Estrategico-Turismo-Sustentable-2025.pdf

Ministerio de Turismo. Presidencia de la Nación (2011). Plan Federal Estratégico de

Turismo Sustentable 2020.2 Recuperado de

http://www.uba.ar/cambioclimatico/download/MinisteriodeTurismodelaN acion.pdf

Naciones Unidas (2019). Objetivos y metas de desarrollo sostenible. Recuperado de: https://www.un.org/sustainabledevelopment/es/sustainable-developmentgoals/

PNUMA (2016). El Acuerdo de París y sus Implicaciones para América Latina y el Caribe: Sumario. Recuperado de: http://euroclimaplus.org/seccionpublicaciones/tipo-de-documentos/estudios-publicaciones-2/el-acuerdo-deparis-y-sus-implicaciones-para-america-latina-y-el-caribesumario/viewdocument/37

Secretaria de Turismo de la Nación. Presidencia de la Nación (2005). Plan Federal Estratégico de Turismo Sustentable 2016. Recuperado de: https://es.slideshare.net/david20/plan-federal-de-turismo-sustentableargentina-2016 